\title{
O PROJETO DA ECONOMIA SOLIDÁRIA E A FORMAÇÃO DA IDENTIDADE DE GRUPO DE UMA COOPERATIVA POPULAR ${ }^{1}$
}

\section{Simone Aparecida Lisniowski}

Mestre em Direito Cooperativo pela UFPR, professora substituta no Departamento de Psicologia da UFPR

RESUMO: Este trabalho analisa a construção da identidade de grupo de uma cooperativa popular na cidade de Curitiba, Brasil. A pesquisa de campo, realizada em 2003, está baseada na história de vida relatada pelos fundadores da cooperativa, e procurou responder como eles constroem sua identidade de grupo em uma experiência de autogestão. Este trabalho ressalta o processo de formação da identidade, o crescente conflito entre as identidades previamente construídas e as identidades em construção do grupo, que gera o seguinte impasse: a prática interna da cooperativa é solidária, mas sua relação com o mercado é de competitividade. Isto porque, quanto mais frágil a identidade do grupo que forma uma cooperativa, mais susceptível ele estará aos valores e relações de poder do mercado, internalizando a ética do capital e perdendo seu caráter solidário e seus valores cooperativos. Este estudo entende que a busca de uma transformação social modifica os sujeitos nela envolvidos e portanto as identidades formadas a partir da experiência subjetiva na prática cooperativa. A análise sugere que, quando os grupos divergem em torno da missão central do projeto da cooperativa, torna-se difícil manter a coesão em torno do projeto inicial. Pode-se observar que dois tipos de projetos estão sendo negociados: o projeto que enfatiza a inclusão social de todos os membros, e aquele que enfatiza a inclusão da cooperativa no capitalismo por meio da adoção dos valores de produção e crescimento econômico.

PALAVRAS-CHAVE: Cooperativa Popular, Economia Solidária, Identidade de Grupo.

${ }^{1}$ Dissertação apresentada no Programa de Pós-graduação no Setor de Ciências Jurídicas da UFPR, 2004. 
Este trabalho consiste na análise dos mecanismos de formação do grupo e suas relações na formação da identidade grupal da Cooperativa $A B C$, fundada em 2000 e funcionando na cidade de Curitiba.

Este grupo nasceu de uma organização das associações de bairro, estimuladas por líderes políticos e pela Incubadora Tecnológica de Cooperativa Popular da Universidade Federal do Paraná (ITCP/Pr).

$O$ estudo se baseia na análise da história de vida de seus sujeitos e na história da formação da cooperativa. A análise da história da cooperativa pretendeu focalizar os aspectos que contribuem para a significação dos discursos e práticas coletivas e, portanto, para construção de uma identidade de grupo.

Foram entrevistados dois homens e cinco mulheres que constituem o grupo de fundadores. A cooperativa iniciou com cerca de 30 pessoas, mas na época das entrevistas, entre junho e julho de 2003, haviam somente 7 cooperados-fundadores participando das atividades. Onze novos cooperados estavam sendo integrados ao grupo naquele período.

A identidade neste estudo é entendida como um processo social mas que é experimentado subjetivamente, ou seja, o eu do sujeito busca uma unidade e neste movimento organiza sua identidade central, mas é um eu individual que compartilha experiências coletivas. No grupo esta identidade individual é negociada e sofre modificações quando as experiências apontam caminhos mais satisfatórios, levando o indivíduo a optar por valores e experiências diferentes das vividas anteriormente. Este estudo parte do pressuposto de que a identidade, ao ser compartilhada, orienta a ação coletiva dos cooperados, pois ela dá ao grupo um sentimento de unidade, de continuidade e de expectativa sobre o comportamento e objetivos a serem alcançados.

Não se pode pensar em modelos de gestão cooperativa e estratégias de intervenção, sem considerar que cada grupo tem sua dinâmica, sua história, sua subjetividade, e são estes aspectos que determinam a coesão do grupo para 0 trabalho cooperativo.

No estudo podem-se observar vários fatores internos como obstruindo a coesão do grupo, entre eles a desconfiança entre os membros, as disputas internas, a descrença na proposta cooperativista e frustrações nas expectativas de trabalho imediato ou lentidão no processo de organização grupal, e as relações de poder. 
Todos estes fatores podem ser apontados como obstruidores do processo de formação da cooperativa e de sua identidade.

$O$ interesse em pesquisar a identidade das cooperativas nasce da necessidade de representação política e jurídica dos novos grupos que formam cooperativas populares hoje. O modelo jurídico atual não contempla as necessidades das cooperativas formadas por trabalhadores, uma vez que o jurídico não contempla os valores solidários e democráticos das cooperativas populares. As cooperativas populares, além de buscar a transformação da condição de vida dos seus integrantes, buscam também uma transformação social. O sistema jurídico que busca representar e dar identidade às cooperativas está, em ultima análise, apoiado nos valores do sistema capitalista enquanto as cooperativas populares estão apoiadas em valores e princípios concretamente solidários por meio de práticas autogestionárias. Esta incompatibilidade fundamental na forma como a cooperativa se vê representada cria uma tensão permanente no bojo da identidade social da cooperativa, uma vez que sua representação jurídica está aquém de tudo o que a cooperativa é.

Observa-se uma discrepância entre aquilo que o jurídico dá conta de representar das cooperativas e aquilo que as cooperativas precisam para se fazer representadas enquanto empreendimento e movimento político. Esta discrepância tem se colocado como um agravante para o sucesso das cooperativas populares porque a falta de tratamento do sistema jurídico condizente com as necessidades reais das cooperativas é insuficiente e incompatível com a realidade, com a prática e com os princípios nos quais a cooperativa se funda e opera.

A Economia Solidária (CATTANI, 2003) na qual estes empreendimentos cooperativos se baseiam, se apresenta como um novo paradigma baseado na solidariedade que nasce do desejo de mudar o quadro de desigualdade e exclusão social das classes pobres. Este paradigma que busca a transformação, surge como resistência ao sistema competitivo do capitalismo e portanto é marginal às normas já instituídas, que estão organizadas de forma a manter a hegemonia de grupos dominantes.

Encontra-se aí a questão central, gerada na contradição entre os paradigmas de organização social, que levou a este estudo: a busca da interpretação de uma experiência solidária, diferente daquela que é promovida pelo 
capitalismo, e que não pode ser representada satisfatoriamente por instituições que não compartilham dessa busca.

A contradição que o sistema jurídico encontra para representar as cooperativas populares é reflexo de profundas contradições sociais geradas pelo capitalismo, que baseia sua organização social na exploração e na desigualdade econômica. As desigualdades geradas pelo paradigma capitalista têm excluído de seu sistema um número de pessoas cada vez maior. O sofrimento resultante desta exclusão está gerando respostas cada vez mais contundentes dos grupos organizados que lutam por mudanças sociais.

Este estudo entende que a busca de uma transformação social modifica os sujeitos nela envolvidos e, portanto, as identidades formadas a partir da experiência subjetiva no contexto social de busca de transformação.

O sistema capitalista, como macroestrutura, abrange todas as relações sociais e produz um sistema de significação que permeia a construção de valores e as concepções de mundo dos sujeitos. Estes valores se colocam de forma abrangente para dar sentido ao tecido social e fundar os sujeitos a partir de uma visão coletiva que reproduz um modo de produção de bens, de valores, da própria subjetividade.

A ideologia capitalista está fundada no individualismo e na concepção de sujeito autônomo e racional. Entretanto, esta não atende às necessidades de todos, e portanto as cooperativas populares buscam uma prática coletiva e valores humanitários para seus integrantes como um novo projeto de organização social, de concepção de mundo e de sujeito.

O movimento cooperativista não é simplesmente um efeito social, mas nasce como uma forma de organização social para responder aos efeitos nocivos do capitalismo e da globalização. A cooperação não diz respeito à natureza do homem, é uma construção cultural na busca de outras formas de relações sociais, a cooperação é uma idealização, um esforço para a democracia, um ideal proposto para que todos possam usufruir os bens produzidos pela sociedade.

O ideal que constroem para o futuro é a busca do novo, e é este ideal que guia a ação do grupo na busca por uma vida melhor. A idealização do futuro pode estar ancorada no real ou ignorar os limites de cada indivíduo e as complexas redes de relações sociais macroestruturais. 
Nesta problemática, coloca-se uma contradição vivida pelos sujeitos nas suas relações dentro do próprio grupo. No momento em que lutam por um lugar no mercado, os cooperativados baseiam-se em experiências prévias de trabalho assalariado ou temporário, cujas concepções de organização do trabalho, de divisão da renda, valor do trabalho, foram anteriormente apreendidas dentro de sua vivência no sistema capitalista. É a partir de suas experiências anteriores que os membros do grupo constroem uma identidade compartilhada, baseada em valores, noções e práticas culturais em comum. Neste novo momento, ao organizar o trabalho em coletividade solidária, terminam por reproduzir modelos de relações de poder e competitividade oriundos de sua experiência anterior no capitalismo.

A repetição de experiências prévias dentro de um modelo competitivo entra em contradição com a prática solidária necessária à cooperativa. Esta contradição ocorre porque, no processo cooperativo, as práticas individuais internalizaram os valores do capitalismo dificultando um consenso baseado na concepção de trabalho cooperativo e participativo.

Para os indivíduos envolvidos na formação de cooperativas solidárias, este crescente conflito, entre as identidades previamente construídas e as identidades em construção do grupo geram o seguinte impasse: a prática interna da cooperativa é solidária, mas sua relação com o mercado é de competitividade. Este impasse marca muitas divergências na concepção e organização do trabalho cooperativo.

As diferenças individuais, de valores e experiências na organização do trabalho, estão constantemente sendo negociadas no grupo, possibilitando assim uma criação coletiva de novas práticas organizacionais. Sem essa negociação, o grupo pode tender a negar as diferenças e buscar no uso de poder a afirmação de interesses individuais ou de pequenos grupos internos.

Percebe-se assim um paradoxo entre o modo de organização do trabalho no capitalismo e o princípio organizador do trabalho cooperativo. Quanto mais frágil a identidade do grupo, que forma uma cooperativa, mais susceptível ele estará aos valores e relações de poder do mercado, internalizando a ética do capital e perdendo seu caráter solidário e seus valores cooperativos.

Nesta tensão, a busca de uma identidade é fundamental para a manutenção da cooperativa, e sendo uma identidade de grupo, sempre haverá a necessidade de por em debate a diferença. 
Se houver no grupo o acolhimento das diferenças individuais na busca de um consenso, a vivência cooperativa pode significar para seus membros um ganho maior do que retorno financeiro, mas também uma realização pessoal. Mas se no processo de formação da cooperativa existir uma tendência de que os discursos de poder de pequenos grupos internos que prevaleçam sobre o consenso, seus membros não se sentirão seguros ao afirmar os valores do cooperativismo, da eqüidade e da luta coletiva, pois haverá uma outra lei dominante, a lei do mercado, da competitividade e da individualidade.

Este paradoxo exige dos sujeitos uma transformação em nível subjetivo para a criação de novos sentidos baseados em sua experiência solidária de autogestão, assim como uma nova experiência identitária. Na cooperativa o sujeito pode experienciar a si mesmo de maneira diferente de um operário na fábrica, porque a organização coletiva possibilita a ele uma maior participação nas decisões e autonomia no trabalho.

A ambigüidade, no estudo sobre identidade está sempre presente. Tanto como ambigüidade interna dos sujeitos envolvidos, seus discursos e práticas, como a ambigüidade do grupo, a cooperativa, na sua relação com o mercado e sua busca de representação jurídica e política.

A ambigüidade interna na cooperativa ocorre porque os interesses de progresso individual convivem com a solidariedade e o trabalho coletivo. $E$ a ambigüidade externa ocorre porque, ao mesmo tempo em que a cooperativa, como projeto emancipatório, pede financiamento e um tratamento jurídico diferenciado, ela é considerada como um empreendimento, e como tal deve concorrer como uma empresa capitalista.

Esta identidade, atribuída para a cooperativa pelo sistema jurídico, a coloca na mesma ordem de uma empresa que opera dentro da lógica capitalista. Esta incongruência leva a acreditar que, para se promover a experiência cooperativa, será necessária a obtenção de todos as características com as quais as outras empresas que não estão baseadas na economia solidária funcionam. Isto dificulta o êxito do projeto, pois seus integrantes,, além de não ter o capital inicial, enfrentam enormes dificuldades para entrar na lógica do mercado sem se desvincular dos princípios solidários em torno dos quais a identidade cooperativa se aglutina. 
Tais desafios estão no âmago das questões que vão definir o quanto a cooperativa será de caráter transformador ou adaptador em relação aos modos de organização impostos pelo capitalismo. As possibilidades que ela encontrará para sua organização interna permeiam os processos que identificam seus sujeitos como grupo.

A construção da identidade de grupo portanto, perpassa os modelos de relações desenvolvidas pelo indivíduo com a cultura capitalista. Ao falar em identidade de grupo na cooperativa, se fala de um processo transformador no qual o sujeito é sua própria criação. A criação de novos aspectos identitários dá um novo sentido ao modo de organização e de produção, transformando os sujeitos envolvidos em criadores culturais.

Por ser uma experiência complexa e que exige a transformação do sistema de valores de seus participantes, supõe-se que a formação da identidade grupal seja o eixo em torno do qual as dinâmicas se articulam. A identidade é também a base na qual os indivíduos se apóiam para se fazer representar, tanto individualmente dentro do grupo quanto enquanto grupo. A identidade do grupo, assim como é para o indivíduo, garante uma imagem unitária para a cooperativa e uma percepção de continuidade do grupo em um passado e em um futuro.

O problema nasce da busca de se entender de que forma os membros da cooperativa se organizam, não apenas nas questões mais práticas do trabalho, mas em torno de valores em comum e de seu sistema de crenças, considerando que os sujeitos não estão buscando somente satisfação material, de suas necessidades individuais, mas também um sentido para sua existência e uma realização subjetiva em sua inserção no corpo social.

Ao buscar uma realização subjetiva, os indivíduos no grupo constroem sentidos compartilhados, na busca de reconhecimento pelo grupo e de reconhecimento de seu desejo.

Portanto este trabalho procurou investigar que processos identificatórios poderiam estar contribuindo para a coesão do grupo analisando a história de vida de seus membros.

O que se coloca em causa é a própria reinvenção da emancipação social. A globalização "tem redefinido os contextos, os objetivos, os meios e as subjetividades das lutas sociais e políticas" (SANTOS, 2002, p.14). A gestão democrática muitas 
vezes suscita instabilidades, mas apesar disto é possível promover a democratização. Quais podem ser os critérios que determinam em que grau as iniciativas constituem alternativas econômicas emancipatórias?

As cooperativas são alternativas que vão contra as formas competitivas de organização capitalistas e podem se consolidar sua organização colocando uma resistência à hegemonia do capitalismo. Porque as cooperativas são uma destas alternativas que "não apontam apenas para a remuneração igualitária dos trabalhadores-donos das empresas cooperativas, mas também para criação de formas de sociabilidade solidárias baseadas no trabalho colaborativo e na participação democrática na tomada de decisões sobre as empresas" (SANTOS, 2002, p.29).

Os novos movimentos sociais tendem a produzir sujeitos que têm uma identidade, que se diferenciam de outros grupos sociais e que aparecem devido ao sistema excludente ao qual estão submetidos.

Estes sujeitos excluídos são, para a organização baseada na racionalidade, sujeitos 'irracionais' que devem mudar, se adaptar para que sejam incluídos. Nas críticas sociais mais amplas analisa-se as relações macroestruturais da economia, do direito e da política como mecanismos de exclusão e de reprodução deste poder baseado na racionalidade. Trazer uma dimensão subjetiva é incluir a experiência individual nas relações sociais e reconhecer as necessidades, as demandas e o desejo dos sujeitos, que constroem, significam e experienciam em seus grupos de pertencimento, neste contexto macroestrutural.

Kelsen apóia o sistema jurídico na ordem normativa, em um sistema de normas que regulam a conduta humana, e a norma fundamental validaria todas as outras normas de conduta. Portanto, para ele, a norma é da ordem do dever-ser, não é uma norma posta por uma autoridade, é uma norma pressuposta. Assim, o direito passa a depender de uma coerência com a norma fundamental.

Pensar as normas como independentes das mudanças sociais, é pensar a idealização da vida em sociedade independente dos sujeitos que participam dela. Pensar a norma como uma natureza autônoma e independente das relações sociais é dar a ela um caráter apolítico. Assim como é apolítico o primeiro significante que vai estruturar o sujeito psicanalítico. Mas somente estes dois momentos 
fundamentais e estruturantes podem ser pensados como apolíticos, a norma fundamental e o significante fundamental.

A identidade de uma cooperativa, analisada do ponto jurídico é vazia de sentido, a identidade é como a 'casca de um ovo' (ENRIQUEZ, 2002) se não for considerado o contexto, a organização social, sem considerar o modo de produção e o papel do sistema jurídico na sociedade. A identidade de uma cooperativa, juridicamente, precisa só se adequar ao sistema, e tornar-se uma tentativa de adequar interesses econômicos de grupos hegemônicos, que excluem aqueles que deveriam estar criando uma organização solidária. Este é também um campo de luta social, sua identidade se forma a partir da experiência e dos valores compartilhados pelos grupos que se formam cooperativamente.

As identificações não ocorrem somente em relação às pessoas individuais, ocorre também em relação aos grupos. O sujeito se identifica com um grupo porque projeta no grupo características idealizadas do seu ideal de eu. Esse grupo pode vir a reconhecer essas características idealizadas no sujeito, dando a ele a possibilidade de realizá-las na relação com o grupo. O grupo pode ser formado por pessoas com características diferentes entre si, entretanto elas se identificam em torno de um ideal, um sentido, um projeto em comum. Por isso, o indivíduo no grupo é capaz de abandonar seus interesses pessoais, por já estar unido ao grupo e por "sentir necessidade de estar em harmonia com eles" (FREUD, 1921, p.103).

A formação da identidade de um grupo ocorre quando elementos desta identificação são compartilhados por todos os membros de um grupo, cada qual significando de maneira individual mas reconhecendo em outros membros semelhanças que os ligam a um projeto idealizado comum. A identidade de grupo se baseia neste ideal em comum mantido pelo grupo, e na razão que os mantém unidos. Ela é o resultado da busca de unidade do grupo e o eixo aglutinador para o projeto de vida compartilhado por seus membros. Sua construção resulta da busca constante da realização deste projeto coletivo. Este imaginário comum, compartilhado por todos os membros, que considera o projeto como ideal e o grupo como seres ideais, mobiliza a crença dos membros para que partilhem de uma mesma ilusão: de que a organização tem uma causa a defender (ENRIQUEZ, 1994).

O processo de construção identitária individual e grupal não está distante das redes de relações macro-estruturais, elas interagem, mas dizem respeito a 
diferentes ordens de relação social. A macroestrutura é uma dimensão importante para contextuar a identidade da cooperativa na história social mais ampla, pois ela tanto é influenciada por valores e idéias coletivas mais amplas como cria ideais, significações, sentidos e valores compartilhados por seus membros, processo este que ocorre na maior parte das vezes inconscientemente.

As dinâmicas, conflitos e impasses encontrados na análise da identidade da Cooperativa $A B C$ indicam que a raiz destes problemas se encontra em uma instância para além do grupo estudado; elas derivam de um problema fundamental na própria identidade do projeto da Economia Solidária, e na identidade das Cooperativas Populares. O problema de identidade da Economia Solidária está repercutindo na formação da identidade do grupo estudado e este estudo ousa inferir que este é um problema conjuntural que pode estar repercutindo na formação das identidades de grupos de outras cooperativas, uma vez que o impasse se coloca na falta de clareza e na ambigüidade do próprio projeto das cooperativas populares.

A Economia Solidária propõe o cooperativismo como forma de organização coletiva para uma transformação social e econômica. Ao apoiar a formação de cooperativas populares, o projeto da Economia Solidária, apresenta uma contradição que têm polemizado as discussões: se por um lado propõe a transformação social, por outro propõe uma adaptação ao sistema capitalista para a sua inclusão.

A Economia Solidária têm ideais que buscam superar o capitalismo. Ao mesmo tempo ela pretende atender a objetivos mais imediatos de geração de trabalho e renda que são, para as comunidades, necessidades urgentes. Observamse aqui dois movimentos distintos. Um deles leva a cooperativa a se adaptar às leis do mercado para se inserir no sistema capitalista enquanto uma organização geradora de renda e trabalho. O outro leva a cooperativa a transformá-lo construindo relações menos competitivas. Neste segundo movimento ela pretende operar dentro de um novo paradigma, tendo a solidariedade como princípio transformador dos sujeitos.

Esta contradição gera uma tensão no grupo e a necessidade de uma negociação interna dos objetivos da cooperativa, na medida em que ela terá que lidar com dois objetivos que são ideologicamente contraditórios: um é a inserção da cooperativa no mercado capitalista, e o outro é a transformação do sistema competitivo e exploratório do capitalismo. 
Por um lado se constrói um ideal de cooperativa baseado na solidariedade e inclusão dos diferentes indivíduos, por outro se mantém o modelo de trabalhador produtivo e competitivo, racional e eficaz da ideologia capitalista

Esta tensão se torna mais conflitante quando os cooperados se dividem entre um e outro objetivo. A Economia Solidária parece apresentar, na sua origem, um problema de ambigüidade interna por não ter clara se a sua missão é incluir a cooperativa no sistema capitalista ou transformar o sistema capitalista em um sistema mais solidário. Se ela buscar a inclusão no sistema capitalista, vai ter que se adaptar as normas desse sistema. Se ela optar por ser transformadora precisa questionar as formas de produção capitalistas e as regras pelas quais ela se insere no mercado. Este paradoxo coloca um grande desafio para as cooperativas populares que para se estabelecerem e crescerem, precisam afirmar uma identidade e uma missão com clareza tanto para o público quanto para seus integrantes.

A partir dessa ambigüidade interna no projeto a proposta da Economia Solidária causa uma oscilação nas cooperativas sobre o seu papel e a sua missão que coloca em risco sua estabilidade, sua coesão e cria uma cisão interna na concepção que os cooperados têm do projeto nas expectativas que ele gera.

No caso desta cooperativa em particular, os líderes políticos que construíram o primeiro referencial de cooperativismo projetaram o ideal de uma grande cooperativa, valorizando o sucesso econômico. Assim, durante a formação da cooperativa, o grupo se divide entre aqueles que enfatizam a solidariedade e os que enfatizam o sucesso econômico. Isto representa um conflito que se acirra quando o grupo precisa tomar decisões internas.

É preciso que os líderes sejam conscientes do valor de sua fala para os indivíduos, e os riscos de uma idealização contraditória para a manutenção dos grupos e da proposta da Economia Solidária.

A partir do momento que a Economia Solidária tiver definido sua missão, entre os líderes, teoricamente ou com as comunidades, como um movimento social, ela deixará claro, para as comunidades que virão, o ideal no qual ela se pauta. Mesmo que a Economia Solidária esteja em um processo de definição do seu ideal, esperando que ele seja uma construção coletiva, enquanto estiver ambíguo, o projeto como um todo está correndo um risco ainda maior de ser temporário, pois está exposto a um poder imperativo do sistema capitalista. Por outro lado, a 
definição de um ideal exterior aos sujeitos é autoritária. O projeto precisa reconhecer a produção de sentidos destes indivíduos como a principal riqueza da cooperativa. Seu ideal deve estar centrado na valorização da busca de autonomia, individualmente e coletivamente.

A pergunta que cabe é a seguinte: a sociedade atual deseja mudar? Se observarmos a forma como nascem as transformações sociais, veremos que elas precisam de uma idéia que corresponda ao desejo da sociedade por uma nova forma de organização social. Os movimentos de transformação social têm em seu cerne o desejo de sujeitos que sentem a necessidade de uma nova organização, que inclua aqueles aspectos da vida humana que não estão sendo satisfeitos. Se a cooperativa atende a esse desejo, se as pessoas estão sentindo necessidade de solidariedade, por que as cooperativas não podem centrar na sua identidade a característica de um movimento social? Se as pessoas sentem apenas necessidade de ocuparem lugares de privilégios, por que então propor um projeto de Economia Solidária?

Um aspecto da identidade que esteve muito presente na cooperativa estava relacionado à sobrevivência, e esta experiência de limiar social é uma conseqüência não de uma situação que foi provocada pelo sujeito, mas de uma conjuntura macroestrutural na qual ele se vê obrigado a se adaptar mas que não entende sua lógica. Os sujeitos estudados demonstraram entender seu problema de sobrevivência como um problema individual, ou seja, estão pautados por um paradigma predominante na sociedade no qual as pessoas tendem a se perceber como sujeitos conscientes, racionais e livres para escolherem seu modo de vida sem perceber que, até mesmo sua identidade está sendo formada por determinantes sociais e econômicos.

Se o ideal da Economia Solidária deve estar pautado na crítica ao capitalismo, será necessário um processo de transformação na forma como o cooperado se percebe como sujeito dentro do sistema capitalista e como ele percebe a cooperativa em relação às outras empresas. Perceber a cooperativa como diferente das outras empresas não inclui, para os cooperados, o ato de criticar estas diferenças. Do ponto de vista dos cooperados, a diferença mais marcante entre a cooperativa e a outras empresas se encontra no capital inicial que as cooperativas populares não têm. 
A 'escolha', a 'opção' por um determinado tipo de ideal está ligada à busca de satisfação narcísica, de necessidades subjetivas, desejos inconscientes não realizados, uma busca própria de cada sujeito, portanto a escolha subjetiva por um ideal é acima de tudo uma busca de realização individual.

O sentimento de frustração por não conseguir ser incluído na sociedade gera nos indivíduos a busca de um sentido para a sua condição social e a construção de explicações para a sua privação. O entendimento que será construído de sua privação, motivará a escolha de um ideal. Existem diferentes formas de se buscar a realização do ideal e a saída da situação de privação.

$\mathrm{O}$ indivíduo tem duas formas de se relacionar com a sua privação. $\mathrm{Na}$ primeira ele se percebe como um indivíduo excluído por razões individuais e vai tentar solucionar essas causas por meio de estratégias individuais para se inserir no sistema capitalista. Se o sujeito entende que a causa de sua privação é individual, ele facilmente assumirá o idealismo individualista da sociedade capitalista como forma de buscar a realização do seu desejo de inclusão e de reconhecimento. Se ele se frustrar, pode elaborar essa frustração e redimensionar o ideal de se adaptar ao sistema capitalista que ele buscava, porém mantendo no sistema seu ideal redimensionado. Como esse ideal de inclusão nasce do sistema já estabelecido, mesmo redimensionado ele estará associado ao sistema no qual nasceu.

Se ele nega este ideal e conseqüentemente toda a estrutura social ao qual o ideal se vincula, isto causará uma perda do sentido e da organização interna do sujeito, a desordem interior fará um movimento de desordem no exterior para construir um novo sentido individual e colocar em prática um novo ideal que o inclua no sistema que se propõe a ser o novo organizador social, e assim realizar o seu desejo de reconhecimento e o reconhecimento do seu desejo.

No segundo, caso o indivíduo percebe sua privação como uma privação coletiva que é causada pelo sistema econômico. Esta percepção tem uma possibilidade maior de gerar um movimento coletivo se vários indivíduos já não acreditam no ideal da sociedade vigente. Se o indivíduo entende que o ideal do capitalismo atende somente à realização de uma classe, e ele é excluído como condição para que este ideal se realize, ele pode deixar de acreditar nesta ordem social como possibilidade para a realização do seu desejo de reconhecimento. A realização do ideal de inclusão social do sujeito pode passar a ser percebida como 
um movimento de transformação de uma ordem social. Mas a busca coletiva de um ideal só se concretiza se atende ao ideal de eu dos indivíduos.

Certos valores foram investidos de um significado que não é consciente e determinam as escolhas inconscientes do sujeito. $O$ indivíduo se identifica com um ideal, assumindo-os, e por isso se torna tão difícil para o sujeito abrir mão de uma organização social sem trazer para dentro de uma nova proposta suas crenças, construções valorativas e seu entendimento de mundo. Ou seja, o sujeito não faz suas escolhas racionalmente e portanto não basta ele se perceber dentro da macroestrutura para ocorrer uma transformação em sua forma de buscar o ideal, existe toda uma dinâmica subjetiva que o faz não saber do seu desejo e estar sujeito a ele. Nesta cooperativa o ideal se mostrou inalcançável, pelo menos em curto prazo. Os cooperados não têm como tornar a cooperativa uma mega-empresa. $E$, ao mesmo tempo, se lutarem por isso terão que 'esquecer' os motivos que levaram muitas pessoas a buscarem a cooperativa: idade avançada (a cooperativa era para os aposentados), trabalhadores sem qualificação, e os valores solidários e de cooperação. Como conciliar valores tão diferentes em um mesmo espaço de trabalho e em uma mesma proposta de organização? Este é o desafio de tornar possível a satisfação de necessidades díspares e a realização do desejo dentro de um contexto de ambigüidades e incertezas.

Depois de ter passado por várias frustrações, o grupo de fundadores construiu uma idealização do passado que está diretamente relacionada à sua história de vida. A imagem construída se refere a uma imagem de si mesmos como lutadores, heróis, guerreiros, que são os fundadores que se sacrificaram pela cooperativa.

O conflito começou a se desenhar na cooperativa quando uma maior diversidade de pessoas foram chamadas para participar do grupo. Inicialmente na fala dos líderes, não parecia haver nenhuma contradição na diversidade de concepções e de idéias que eles reuniam em um mesmo discurso sobre a cooperativa. O grupo que foi chamado para participar da cooperativa era composto por mulheres aposentadas ou com idade avançada e a maioria dos cooperados não tinham experiência nem qualificação para o trabalho. Portanto, quando o grupo decidiu montar caixas de madeira, não poderia exercer a maioria das atividades que o processo de produção exigia. Muitas cooperativas são formadas a partir de um 
grupo de prática, que exerce uma atividade similar ou complementar e que apresenta uma certa homogeneidade na experiência e conhecimento dos seus membros.

Atualmente, a concepção que defende que a produção é mais importante para a cooperativa entra em choque com os ideais de solidariedade e inclusão social que, no passado, defendiam que a cooperativa era para aposentados e pessoas que não conseguiam se inserir no mercado de trabalho. Estes ideais motivaram estas pessoas a se vincularem à cooperativa e nela participarem ativamente. A análise sugere que, o ideal fundador da cooperativa, está hoje, sendo negociado nos conflitos do presente. O objeto idealizado e perdido dá lugar a um processo de reconstrução do projeto comum do grupo por meio de uma busca de remodelações e reajustes dos projetos individuais para que estes se acoplem no projeto grupal. Pode-se observar que dois tipos de projetos estão sendo negociados: o projeto que enfatiza a inclusão social de todos os membros na cooperativa, e aquele que enfatiza a inclusão da cooperativa no capitalismo por meio da adoção dos valores de produção e crescimento econômico.

A transformação sempre será uma ação construída pelo sujeito a partir das possibilidades e alternativas que estão à sua mão. Porém, a adaptação e a transformação devem estar subordinadas a um sistema de valores que não perca a perspectiva do ideal solidário a ser vivenciado e valorize a subjetividade daqueles que participam e criam a prática cooperativa. No momento em que o grupo está em conflito e vivendo a ambigüidade, para qual paradigma ele está tendendo a assumir? A busca de uma estabilidade é uma necessidade para o grupo organizar suas ações. O movimento que busca estabilidade está presente em todos os grupos. Mas a cooperativa se vê diante da tarefa de conjugar dois paradigmas e subordinar um ao outro, ou seja, ela deve ser capaz de perceber o paradigma da competitividade estando a serviço da busca da prática solidária. Se os sujeitos puderem apreender esta perspectiva, ela oferecerá uma solução para o seu conflito estrutural. A Economia Solidária precisa oferecer um diferencial mais forte do que a inclusão oferecida pelo sistema capitalista. Esse diferencial tem que ser a marca da Economia Solidária. Qual é o diferencial? O que o capitalismo não oferece para os seus sujeitos?

O projeto da cooperativa propõe não somente a mudança da condição econômica destas pessoas, mas também sua forma de se relacionarem. $E$ ao mesmo 
tempo em que oferece a possibilidade de mudar a condição de vida, também introduz uma mudança nos lugares ocupados por elas na sociedade, mudando sua experiência de identidade. Estudos a respeito dos aspectos intrínsecos à cultura do trabalho solidário devem ser realizados, uma vez que o modelo cooperativo impõe muito além de soluções de geração de renda. Ele traz mudanças profundas na forma como seus sujeitos interagem, percebem o mundo e se percebem dentro dele. $O$ sujeito da cooperativa pode ser valorizado por meio do resgate da criatividade, da autonomia, da participação, do respeito à diversidade e da solidariedade. $\mathrm{Na}$ experiência da empresa, os indivíduos foram muito massacrados e treinados para suprimir os aspectos de expressão individual de sua identidade. Eles não conseguem valorizar estes aspectos em si ou nos outros, e por isso não conseguem perceber que a diversidade de contribuições é o bem mais valioso que pode haver na cooperativa.

O indivíduo que se entrega totalmente para o projeto não espera apenas o retorno material, na medida em que houve um investimento de sonhos e ideais. $O$ que ele também espera é o retorno de uma satisfação inominável em poder expressar sua individualidade e contribuir de uma maneira única no todo. Ele espera exercer a liberdade de expressão que nunca experimentou dentro do modelo de produção capitalista. A dificuldade que se coloca na construção desse novo paradigma é que ele só pode ser apreendido na experiência dessa liberdade, baseada no respeito à diversidade das contribuições dos indivíduos. Ao serem eles, os grandes protagonistas dessa construção, se perdem em paradigmas que sua história anterior oferece como referência, na falta de experiências para inovar uma prática de trabalho e romper com a antiga.

Eles se deparam com este grande desafio: o que se tem a ganhar talvez seja muito maior do que a inclusão em uma ordem que já existe. Mas apontar o caminho para uma nova ordem. Criar o novo para nele já estar incluído. Neste novo paradigma podemos encontrar um novo sujeito, um sujeito que não deposita os investimentos e expectativas apenas no retorno material, mas valoriza como riqueza que não se abre mão: o desejo de realizar e o prazer de compartilhar na ação participativa e solidária o ideal que se busca.

Viver isso no trabalho é o que todo mundo quer, até mesmo os incluídos, pois é o que o capitalismo nega ao seu sujeito. Sejam ricos, pobres ou excluídos. Os sujeitos do paradigma capitalista não conseguem experienciar este tipo de riqueza 
dentro do sistema. É claro que a cooperativa têm uma missão prática, concreta de assegurar a renda, os meios de vida, a geração de trabalho, mas isto seria muito pouco para se desejar para os seus sujeitos. Isto é só o princípio do que os indivíduos querem para si e para seus filhos.

Não é o fato de serem excluídos que tira deles o sonho, o ideal, o desejo de criação. E certamente seria um erro repetir o sistema capitalista ao se tentar criar uma cooperativa que operasse dentro de um paradigma de produção e reprodução, que vai suprimir esta dimensão humana que aqui chamamos de riqueza. Esse sujeito que hoje luta para nascer não pode abrir mão dessa possibilidade de construir novos sentidos. O grande desafio que se coloca é, se nas cooperativas populares, que se organizam hesitantes, neste momento de ocaso, se desses tímidos ensaios, surgirá esse novo sujeito, fruto de tudo que resultar da prática neste novo paradigma.

\section{REFERÊNCIAS BIBLIOGRÁFICAS}

CATTANI, A. A Outra Economia. Porto Alegre: Veraz Editores, 2003.

ENRIQUEZ, E. Vida Psíquica e Organização. Rio de Janeiro: Editora FGV, 2.ed., 2002.

ENRIQUEZ, E. O Vínculo Grupal IN: Psicossociologia - análise social e intervenção. Petrópolis: Vozes, 1994

FREUD, S. Psicologia de grupo e análise do ego. In: Edição standard brasileira das obras psicológicas completas de Sigmund Freud. Rio de Janeiro: Imago, v. XVIII (1921), 1980.

KELSEN, H. A Democracia. O conceito de Estado e a Psicologia Social: com especial referência à teoria de grupo de Freud. São Paulo: Martins Fontes, 2000.

SANTOS, B. (org.) Produzir para Viver: os caminhos da produção não-capitalista. Rio de Janeiro: Civilização Brasileira, 2002. 